\title{
ARTHUR MILLER E SUA DRAMATURGIA: A SHOÁ COMO UM PONTO DE VIRADA
}

\section{ARTHUR MILLER AND HIS DRAMATIC WORKS: THE SHOAH AS A TURNING POINT}

Thiago Pereira Russo*

\section{Resumo}

Este artigo discute a essência dramatúrgica de um dos autores canônicos mais importantes do teatro norte-americano, Arthur Miller. Mesmo que não seja possível mergulhar no universo judaico através de seu corpo de trabalho, é possível identificar elementos da cultura judaica presentes não somente em suas peças teatrais, mas também em sua identidade. O contato com as questões da Shoá aflora sua judeidade e conduz Miller a um ponto de virada em sua criação dramatúrgica, em que a responsabilidade pelos problemas da sociedade passa a ser atribuída não somente ao sistema, mas ao indivíduo, o que aproxima Miller a um humanismo judaico.

Palavras-Chave: Arthur Miller, Humanismo Judaico, Teatro, Shoá.

\begin{abstract}
This article discusses the dramaturgical essence of one of the most important canonical authors of the American theater, Arthur Miller. Even if it is not possible to delve into the Jewish universe through his body of work, it is possible to identify elements of Jewish culture present not only in his plays, but also in his identity. By getting in touch with the issues of the Shoah his Jewishness springs and leads Miller to a turning point in his dramaturgical creation, in which the responsibility for the problems of society is to be assigned not only to the system but to the individual, approaching Miller to a Humanistic Judaism.
\end{abstract}

Keywords: Arthur Miller, Humanistic Judaism, Theater, Shoah.

\footnotetext{
* Psicanalista, mestre e doutorando em Estudos Linguísticos e Literários em Inglês (FFLCH-USP) e membro da The Arthur Miller Society, nos Estados Unidos. Foi palestrante convidado para o Arthur Miller Centennial em Nova Iorque, em 2015.
} 
O ano de 2015 marcou um importante momento não somente para a história do teatro judaico-americano, mas também para a arte engajada. Cem anos se passaram desde o dia 17 de Outubro de 1915, data em que o dramaturgo norte-americano Arthur Miller nasceu. Com ele, nasceram também importantes trabalhos que, dentro e fora dos palcos, se solidificaram na escritura de peças, romances, contos, ensaios e um engajamento político de suma importância. A presença de um dramaturgo como Arthur Miller nos Estados Unidos representa um considerável avanço no campo das ideias políticas, culturais, sociais e históricas não somente de seu país natal, mas do mundo todo. A força centrífuga de uma dramaturgia como a de Arthur Miller incomoda por tocar em questões que se apresentam aparentemente externas ao indivíduo, mas que o tornam parte essencial tanto de suas causas como de suas consequências. Tony Kushner, uma das vozes mais importantes e politizadas do mundo teatral judaicoamericano, ao fazer uma homenagem a Arthur Miller após seu falecimento em 2005, proferiu as seguintes palavras: “(...) Arthur focused his critical gaze, and located his sense of political struggle, within the arena of an individual consciousness, in an important sense his own individual consciousness"

Tal olhar crítico, cuja essência está na esfera da consciência individual (mas, simultaneamente, ligada à consciência da esfera coletiva), está fortemente presente em todo o trabalho que Arthur Miller realizou dentro e fora dos palcos. Nesse ponto, entre tantos outros, Miller se aproxima da sua figura de inspiração maior, o pai do drama moderno, o escandinavo Henrik Ibsen. Ambos os dramaturgos, inicialmente, não foram bem aceitos pelos críticos e precisaram enfrentar censuras ríspidas aos temas e formas de suas peças. Ao mesmo tempo, os dois se mostraram vitais àqueles que ainda buscam ter um pensamento crítico que vocifera contra questões delicadas que - sendo, na verdade, trans-históricas e profundamente humanas - permeavam ambas as sociedades, a escandinava e a norte-americana. Arthur Miller teve uma carreira bastante sólida e resistiu às críticas, às questões comerciais e à censura imposta pela $\mathrm{HUAC}^{2}$, que o acusou de comunismo e o apelidou de Un-American, o dramaturgo antiamericano.

Miller permaneceu fiel, ao longo de sua carreira de dramaturgo, a uma tradição de dramaturgia em que o estudo de Ibsen e de grandes tragediógrafos gregos era significativo, e

\footnotetext{
${ }^{1}$ Tradução do autor: “(...) Arthur focou seu olhar crítico e localizou seu senso de luta política dentro da arena de uma consciência individual - em um sentido importante, sua própria consciência individual".

${ }^{2}$ HUAC é o acrônimo que designa a House Un-American Activities Committee, cuja correspondência em português é Comitê de Atividades Antiamericanas.
} 
ele se tornou, então, um dos dramaturgos mais importantes dos Estados Unidos. Desde o tempo em que estudava na Universidade de Michigan (1934-1938), ainda como graduando no curso de letras, Miller já dava sinais de seu apreço por tal tradição e desenvolveu sua dramaturgia apoiado em uma relação dialética entre forma e conteúdo. Em sua trajetória dramatúrgica, experimentalismo formal e atrelamento a temas específicos foram marcas fortes de sua arte, que buscava sempre retirar as pessoas da letargia, explicitando não somente o que a sociedade é, mas também seu funcionamento ${ }^{3}$. Sua percepção aguda do funcionamento da sociedade e suas questões se traduz em sua extensa dedicação aos múltiplos temas que essa mesma sociedade apresentou em diferentes momentos históricos: Miller falou sobre a Grande Depressão, sobre o Macarthismo, sobre o Sonho Americano, sobre a Shoá e sobre muitas outras questões.

Um dos aspectos mais interessantes sobre sua identidade e sobre como ela se imprime em seu corpo de trabalho é sua judeidade. Esse ponto, aliás, possui contornos curiosos e bastante enriquecedores para a compreensão do que Miller produziu e do tipo de reflexão que provocou.

\section{Miller, Judeidade e Judaísmo}

A relação de Miller com o judaísmo é muito curiosa. Quando nos dirigimos para o mundo dramatúrgico de um dos maiores cânones do drama moderno americano, não é possível adentrar profundamente o universo judaico (laico ou bíblico). Entretanto, há diversos elementos subjacentes que atestam a presença da judeidade de um autor que jamais explicitou tal essência, mas que também nunca a negou. Sua identidade literária, segundo nos lembra Feldman, possui uma dupla oscilação, a qual

(...) obrigatoriamente resvala e oscila entre a influência cultural judaica e o mito americano (American Dream). Enquanto a primeira é expressa nas obras através de metáforas bíblicas imbricadas à visão existencialista e humanista do dramaturgo, o segundo é exposto através de referências feitas à Grande Depressão (1929), ao macarthismo e às críticas ao fracasso de uma sociedade pautada pelo consumismo, visão de lucro e busca do sucesso. (2012, p. 2)

\footnotetext{
${ }^{3}$ Sua dramaturgia, comumente chamada de "social", é, segundo Mason, "política", visto que "enquanto o drama social é sobre a sociedade, o drama político é sobre sua dinâmica: suas lutas, sua dialética e sua evolução" (2011, p. 2).
} 
Essa dupla oscilação que caracterizou fortemente a produção teatral milleriana foi a responsável pelo grande destaque de Miller dentro de seu país, o qual, posteriormente, lhe conferiria o status de um dos autores canônicos do drama moderno americano ${ }^{4}$. Mesmo tendo recebido, no início, críticas negativas às peças que escreveu, essa dupla oscilação materializou-se em muito do que foi escrito em diferentes gêneros (dramático, romance, ensaio etc.) e, principalmente, naquilo que a crítica majoritária do dramaturgo convencionou chamar de "o grande quarteto": Todos eram meus filhos (1947), Morte de um caixeiro viajante (1949), As feiticeiras de Salém (1953) e Um panorama visto da ponte (1956). Entre as peças do grande quarteto, vale destacar, brevemente, as duas que são mais conhecidas tanto pelo público dos Estados Unidos quanto mundialmente, nas quais é possível detectar traços relevantes da identidade que une sua judeidade a seu americanismo: Morte de um caixeiro viajante e As feiticeiras de Salém.

A primeira apresenta a história de Willy Loman (uma das personagens mais importantes do teatro americano), que é um vendedor. Willy encontra-se já mais velho e, não querendo admitir para sua família e para si mesmo que era descartável para o capitalismo, cria um mundo ilusório que oscila entre as memórias do passado e a frustração do presente. Para piorar, Willy é demitido e, como mecanismo de defesa e de negação, agarra-se às questões e memórias que, um dia, o tornaram uma peça-chave na busca do sonho americano do sucesso. Por fim, a saída trágica que Miller confere a seu protagonista é um aparente acidente de carro, que, na verdade, é um suicídio. É nesse ato estarrecedor que a icônica personagem Willy Loman vê uma saída não somente para si, mas para garantir que o dinheiro de seu seguro de vida possa pagar a hipoteca de sua casa e manter a família. O renomado estudioso de Miller, Dennis Welland, explica que a peça possui traços judaicos e que o fato de Miller não ambientá-la em um lar explicitamente judaico confere uma autenticidade ímpar à peça ganhadora do prêmio Pulitzer. Para o estudioso, o cuidado de Miller em não declarar Willy

\footnotetext{
${ }^{4}$ É importante frisar que Miller se consolida como um dramaturgo de renome exatamente em 1947, com a peça Todos eram meus Filhos, mas, anteriormente, em 1945, já tinha feito grande sucesso com um trabalho que, para muitos, indicava o potencial romancista de Miller. O romance em questão é Foco, que trata da questão do antissemitismo nos Estados Unidos na década de 1950 e é um dos livros de ficção mais importantes já escritos sobre o preconceito contra os judeus.

${ }^{5}$ Termo frequentemente mencionado em referência às peças que foram escritas no período de 1947 a 1956 , também conhecidas, entre os críticos de Miller, como early plays ou peças iniciais. Tony Kushner as compilou em um único volume e as publicou pela editora Library of America, em 2006, sob o título Arthur Miller: collected plays 1944-1961, coleção que traz também o conto The misfits (1961) - Os desajustados, em português. Todas as peças que compõem o grande quarteto possuem tradução em língua portuguesa: Todos eram meus filhos (1947), Morte de um caixeiro viajante (1949), As bruxas de Salém (1953) e Um panorama visto da ponte (1956).
} 
Loman como judeu foi um ganho; pois, ao proceder de tal modo, ele responsabiliza o indivíduo por si, e não por sua especificidade (ser vendedor, ser judeu, ser representante de qualquer grupo). Além do mais, a peça ressalta, inequivocamente, a capacidade de um sistema transformar em sucata aquilo que, um dia, era tido como elemento essencial de seu funcionamento. Se há ecos que, porventura, possam ser atribuídos à ética bíblica, isso se deve mais à amplitude do cânone do que à peça em si.

As feiticeiras de Salém apresenta a "caça às bruxas", ocorrida em Salém, no estado de Massachusetts, em 1692. A peça, entretanto, usa esse contexto apenas como pano de fundo, pois ela esboça uma analogia com a situação do macarthismo em que o país se encontrava na década de 1950. Na peça, John Proctor, um proprietário de terras, tem um caso com sua criada, Abigail Williams. A peça se inicia quando as meninas de Salém (uma comunidade puritana) são flagradas em um ritual pagão na floresta. Em choque, algumas das garotas entram em um quadro típico de histeria, com paralisia, perda de voz e sono profundo. A partir de então, abate-se sobre a cidade a crença de que o demônio está entre os cidadãos. A solução encontrada para que cada um se absolva dos pecados é a acusação do outro, e essa mesma dinâmica refletia o que os apoiadores diretos e indiretos do macarthismo faziam. Na trama, Abigail Williams se utiliza de sua confissão de ter tido pacto com o demônio, mas garante sua salvação ao incriminar a esposa de seu ex-patrão, na esperança de que esta fosse para a fogueira. Ao escrever a peça, Miller criticou duramente a conduta de seus conterrâneos em 1950, que se deixaram varrer pela histeria anticomunista e feriram, copiosamente, valores éticos e morais tão caros ao ser humano. Comentando As feiticeiras de Salém, Noemia Fryszman mapeia e analisa a ética judaica engendrada nas ações do protagonista da peça, John Proctor. Em seu brilhante ensaio sobre a influência do teatro ídiche na cultura americana, a autora ressalta que é possível detectar, nas criações dramáticas norte-americanas produzidas por judeus, um código ético comum que guiava a conduta das personagens: o "código" do mentshlihcait, o qual explicita o escopo do humanismo judaico. Novamente, Feldman nos fornece uma importante reflexão sobre as implicações da dinâmica envolvida na construção da personagem:

A trajetória que a personagem terá de percorrer de man a mentsh, pautada no código, darse-á através de duras provas que, quando superadas, torná-la-ão moralmente fortalecida, levando-a a encontrar o sentido da sua vida. O código do mentshlihcait atribui ao homem a responsabilidade pelos seus pecados, ao escolher o mal, e não o bem. A vitória do mal, porém, não é permanente, pois resulta de pressões externas ou de fragilidade moral 
passageira, findas as quais o bem triunfará. É de crucial importância a responsabilidade do homem pelo seu semelhante, e este código não é apenas impregnado de elementos judaicos da cultura do shtétel, mas dos valores éticos que têm sua origem no grande bem comum tanto para os judeus asquenazitas como sefaraditas: a Torá. $(2012$, p. 6)

Assim, Miller assume mais fortemente sua judeidade e os valores judaicos de suas peças - especialmente, no período conhecido por grande parte dos críticos como segunda fase. Chamaremos de primeira fase o período que engloba as peças conhecidas como primeiras peças ou o grande quarteto, enquanto denominaremos segunda fase o período que engloba as peças de 1964-2004, o qual constitui o que os críticos convencionaram chamar de late plays ou peças tardias.

\section{A essência judaica das peças tardias}

Tanto os pesquisadores estrangeiros quanto os conterrâneos de Arthur Miller conhecem, publicam e discorrem sobre as peças da primeira fase como se sua carreira (e suas preocupações sociopolíticas engendradas em sua dramaturgia) se encerrasse após a publicação de Um panorama visto da ponte, em 1956 ${ }^{6}$. Contudo, como nos diz Christopher Bigsby, crítico literário britânico e biógrafo de Arthur Miller, as peças mais importantes e maduras estão justamente na segunda fase, período no qual o humanismo judaico e o ativismo político e literário de Miller encontraram ampla expressão e reconhecimento em solo europeu, principalmente na Inglaterra ${ }^{7}$. Bigsby mapeia a situação de Miller dentro e fora dos Estados Unidos:

(...) curiously he had fallen out of favour in his native America for the previous thirty years. His new plays were not well received even as his classic plays of the 1940s and 50s were taught in schools and universities and regularly revived. Elsewhere in the world, however, his plays of the 1970 s, 80 s and 90 s found a ready audience. $(2005, \text { p. } 1)^{8}$

\footnotetext{
${ }^{6}$ Chama-nos a atenção a quantidade de coletâneas, estudos, simpósios, palestras, filmes e encenações dedicados às peças da primeira fase de Miller e a inversamente proporcional falta de referências relativas à segunda fase.

${ }^{7} \mathrm{Na}$ virada do milênio, dramaturgos, atores, diretores e críticos britânicos elegeram Arthur Miller como o dramaturgo mais significativo do século XX, incluindo duas de suas peças (Morte de um caixeiro viajante e As feiticeiras de Salém) na lista de dez melhores peças.

${ }^{8}$ Tradução do autor: “(...) Curiosamente, ele havia caído em desuso em sua América natal pelos trinta anos anteriores. Suas novas peças não foram bem recebidas, mesmo quando suas peças clássicas dos anos 1940 e 50 eram ensinadas nas escolas e universidades e regularmente reencenadas. No resto do mundo, no entanto, suas peças dos anos 1970, 80 e 90 encontraram um público pronto".
} 
Um exemplo significativo do que nos diz Bigsby sobre essa rejeição por parte dos americanos é a peça The ride down Mount Morgan (1991), que teve sua estreia em Londres e chegou aos Estados Unidos somente sete anos depois. Escrita em 1994, Broken glass, que versa sobre a Kristallnacht, a noite dos cristais $^{9}$, também teve fora do solo americano maior abertura e melhor acolhimento. Enquanto Broken glass teve uma recepção crítica pobre em Nova Iorque, a mesma peça ganhou o Oliver Award, na Grã-Bretanha, como melhor peça do ano.

Tais peças da segunda fase constituem uma mudança na forma como Arthur Miller se comporta (seu ativismo político e preocupações humanitárias tornam-se mais explícitos) e na sua forma de escrever (experimenta novas formas e gêneros, como o vaudeville e a comédia). Parece haver, nas peças tardias, uma transição de um Arthur Miller que, até então, centralizava a responsabilidade pelos problemas na sociedade para um que, aos poucos, a transfere para o homem, sem, porém, se desviar do eixo societário. Essa posição, próxima a uma espécie de existencialismo humanitário, tem como tema central a questão da responsabilidade e se alia à posição política ímpar de Miller e a seu talento extraordinário de traduzi-la para a forma de peças. Há um consenso entre críticos e pesquisadores - e mesmo na autobiografia do dramaturgo - de que $a$ Shoá e as visitas de Miller ao campo de concentração de Mauthausen tenham mudado a sua visão com respeito àquilo que o homem é capaz de fazer. A partir de então, Miller passa a discorrer sobre a essência do homem de uma maneira diferente daquela materializada em sua dramaturgia até aquele momento. Falando sobre tal período, que se inicia em 1964, com a escritura de Depois da queda, essa mudança é notada e explicada por Bigsby nos seguintes termos:

Once, in the 1930s, he had embraced a chiliastic view, looking for an immediate transformation of society, a redemptive revolution of thought and action such as that advocated by Norman Thomas, six times socialist candidate for the presidency of the United States, whose cry was 'Socialism in our time'. Now, he had moved to what Max Weber called an ethic of responsibility. This remained his position, but in the context of the Holocaust (as reflected in After the Fall, Incident at Vichy, Playing for Time and Broken Glass) he was prepared to grant its moral complexity. (...) The progressive vision that had driven him through the 1930s, 40s and 50s, had seemingly foundered (...). $\left(2013\right.$, p. 13) ${ }^{10}$

\footnotetext{
9 A noite dos cristais ficou historicamente conhecida, pois, na noite de 9 de Novembro de 1938, diversos pogroms ocorreram na Alemanha e Áustria, resultando na destruição de sinagogas, lojas judaicas e agressões aos judeus.

${ }^{10}$ Tradução do autor: "Uma vez, na década de 1930, ele havia abraçado uma visão quase que sagrada, bucando uma transformação imediata da sociedade, uma revolução redentora de pensamento e de ação, como a defendida
} 
Para o dramaturgo, assim como para muitos romancistas judaico-americanos do pósguerra, a Shoá é o equivalente moderno da Queda, a inexorável realidade do mal. Quando Miller retornou do Julgamento de Frankfurt, percebeu que o tema da culpa do sobrevivente estava emergindo, o qual se materializaria em seu gigantesco texto Depois da Queda e representaria uma grande mudança, como Bigsby atestou, no que diz respeito, principalmente, aos temas mais abertamente judaicos.

Essa transformação, que resultou, na década de 1960, na escrita de três peças, foi, contudo, atacada por críticos norte-americanos, que diziam que Miller parecia estar em descompasso, fora de sintonia com seu tempo: em vez de falar sobre o Vietnã ou sobre os direitos civis, Miller escolheu falar sobre o macarthismo e a Shoá, em Depois da Queda (1964) e Incidente em Vichy (1964); e sobre a Depressão em The price (1968) ${ }^{11}$. Entretanto, Miller argumenta, em Timebends (sua autobiografia, escrita em 1987), que a negação, presente nas três peças, era o problema central daquele momento. Era justamente a negação que estava por trás da atitude americana perante a questão da raça, facilitando também a realização de uma guerra imoral no sudeste da Ásia ${ }^{12}$. Seu posicionamento políticodramatúrgico, rotulado por grande parte dos críticos como "anacronismo histórico", levou-os a não se esforçarem para compreender o que estava além do aparente. Bigsby comenta os efeitos de tal posicionamento:

As a consequence, for some he seemed the product of another age (...). In Europe, however, where the past is never dead, where history lives on the pulse and totalitarianism has either been centre stage or standing in the wings awaiting its cue, Miller's seems in every way a modern voice. (...) He stages the lives of those baffled by an existence whose meaning frequently evades them but whose struggle to understand

\footnotetext{
por Norman Thomas, seis vezes candidato socialista à presidência dos Estados Unidos, cujo grito era "socialismo em nosso tempo". Agora, ele tinha mudado para o que Max Weber chamou de uma ética da responsabilidade. Esta permaneceu sua posição, mas, no contexto do Holocausto (como refletido em After the Fall, Incident at Vichy, Playing for time e Broken glass), ele estava preparado para conceder sua complexidade moral. (...) A visão progressista que ele tinha conduzido durante os anos 1930, 40 e 50 anos, tinha aparentemente naufragado (...)".

${ }^{11}$ Sua peça de maior sucesso nos anos 1960 foi justamente The price, que, simultaneamente, se aproxima da arrebatadora Death of a salesman e de All my sons, na qual o passado é lentamente revelado, procedimento típico da técnica analítica, de Henrik Ibsen.

${ }^{12}$ Nos anos 1960, Arthur Miller tornou-se ativamente envolvido no movimento antiguerra. As universidades de Michigan, Yale e West Point o convidaram para falar sobre a guerra. Em 1965, por exemplo, Miller tornou-se presidente do PEN INTERNATIONAL (uma organização literária internacional que advoga em favor de uma imprensa livre e contra a censura e opressão de escritores), tornando-se o primeiro americano a alcançar esse posto.
} 
and prevail is one of the justifications for an art which itself seeks form in seeming chaos $^{13} .(2013$, p. 2)

\section{Considerações finais}

Um fato que nos chama a atenção é que a dramaturgia tardia de Miller (e, portanto sua judeidade mais explícita) é mais celebrada em solo europeu do que em sua própria terra. Michael Billington ${ }^{14}$, buscando compreender a diferença, forneceu, no The Guardian, a seguinte crítica cultural:

[Miller] retains to this day [...] the liberal's faith in human perfectibility. But, for all the quintessential American-ness of his themes, he has the European dramatist's belief in the need to ask daunting questions rather than provide comforting answers. In the end, that to me is what makes him such a fascinating writer: he remains totally anchored in American life while challenging almost all of the values and beliefs that make the society tick. He is the late twentieth century's most eloquent critic of the devalued American dream ${ }^{15}$. (1990, p. 189)

Por um lado, podemos entender esse desinteresse ou cegueira por parte da crítica americana com base no que Billington argumenta e, por outro, através de uma desvalorização deliberada do que se apresenta como "político" ou "crítico" demais para os americanos. A redução de peças historicamente ricas a aspectos que em pouco ou em nada contribuem para a compreensão da força literária de Miller é um dos padrões de análise mais comuns nos Estados Unidos. Tais leituras e análises insipientes vão das leituras taxonômicas às psicologizantes e/ou biográficas, as quais parecem causar êxtase nos que as fazem e naqueles

\footnotetext{
13 Tradução do autor: "Como consequência, para alguns ele parecia o produto de outra era (...). Na Europa, no entanto, onde o passado nunca está morto, onde a história é latejante e o totalitarismo ou foi o centro do palco, ou está à espreita esperando uma deixa, Miller parece, em todos os sentidos, uma voz moderna. (...) Ele encena a vida daqueles confusos por uma existência cujo significado frequentemente lhes escapa, mas cuja luta para entender e prevalecer é uma das justificativas para uma arte que busca forma no aparente caos".

${ }^{14}$ Considerado o mais antigo crítico de teatro da Grã-Bretanha, Billington, que também é biógrafo de Harold Pinter, escreve para o The Guardian desde 1971.

${ }^{15}$ Tradução do autor: "[Miller] mantém até hoje [...] a fé liberal na perfectibilidade humana. Mas, apesar de toda a quintessência da americanidade de seus temas, ele tem a crença do dramaturgo europeu na necessidade de fazer perguntas assustadoras, em vez de fornecer respostas reconfortantes. No final, isso, para mim, é o que faz dele um escritor tão fascinante: ele permanece totalmente ancorado na vida americana, ao mesmo tempo desafiando quase todos os valores e crenças que fazem a sociedade se mover. Ele é o crítico mais eloquente da segunda metade do século XX do decadente sonho americano".
} 
que as leem. Essas leituras, a propósito, começaram a circular e a se espalhar por todos os cantos e para diversos autores ${ }^{16}$.

Perante a abordagem psicologizante e biográfica, Daniel, filho de Arthur Miller e portador de Síndrome de Down, e Marilyn Monroe, sua ex-esposa, ocupam lugar central na tabloidização da vida. Em vez de olhar para o objeto, a crítica enxergava (e continua enxergando) aspectos superficiais, ignorando o que havia (e o que há) de mais primordial e central na dramaturgia de Miller: a essência política de suas peças e, principalmente, o papel que sua judeidade desempenhou na sua trajetória. $\mathrm{O}$ trabalho dele é constantemente minado pela psicologização e tabloidização da vida privada, pois esses elementos tornam-se ativos e atrativos da e para a indústria cultural - não somente no que diz respeito às peças de Arthur Miller, mas em relação a peças de outros dramaturgos. São ativos e atrativos por reduzirem as análises a padrões cognitivos relativamente simples e dicotômicos, além de garantirem sucesso comercial. Terry Eagleton, em A função da crítica, oferece uma lúcida explicação para a adesão em massa à crítica aos ditames do sucesso comercial: "A própria crítica incorporou-se à indústria cultural, como uma espécie de relações públicas sem remuneração, uma parte dos requisitos necessários a qualquer grande empreendimento corporativo" (1991, p. 99).

Compreendendo esse cenário desolador como parte constituinte da filosofia/ideologia da Broadway, a obra de Miller se insere na contramão do poder hegemônico e excludente de tal mentalidade. Seu forte compromisso com um humanismo judaico o impulsionou a buscar temas mais complexos e abstratos, que ainda não encontraram espaço suficiente de debate, de reflexão, de análise e de encenação. Sua judeidade e seu compromisso infindável com valores éticos e morais permanecem sendo elementos de interesse maior ao seu público e aos críticos.

\footnotetext{
${ }^{16}$ Os exemplos de tal cenário são fartos, estendendo-se mesmo ao Brasil. Para mencionar um breve exemplo de um autor também canônico do teatro norte-americano, as personagens de Tennessee Williams sofrem um silêncio imposto por uma violência (normalmente, aquela que os exclui das relações de produção) e são enxergadas como vítimas de sentimentos desencontrados de amor, afeto e de solidão.
} 


\section{Bibliografia}

BALAKIAN, J. The Holocaust, the Depression, and McCarthyism: Miller in the sixties. In: BIGSBY, Christopher (Ed.). The Cambridge companion to Arthur Miller. Cambridge: Cambridge, 1999.

BIGSBY, C. Arthur Miller and Company. London: Methuen, 1990. . Arthur Miller: a critical study. Cambridge: Cambridge University Press, 2005. . Arthur Miller: 1962-2005. Ann Harbor: The University of Michigan Press, 2013.

EAGLETON, T. A função da crítica. São Paulo: Martins Fontes, 1991.

FELDMAN, A. D. S. O Éden de Arthur Miller - elementos bíblicos e existencialistas na peça “A criação do mundo e outros negócios": seriedade e crítica em uma obra cômica. 279f. Tese de Doutorado - Faculdade de Filosofia, Letras e Ciências Humanas da Universidade de São Paulo. São Paulo, 2006.

- Elementos bíblicos nas peças de Arthur Miller. 2012. Disponível em:

$<$ https://bibliaseliteraturas.files.wordpress.com/2012/11/elementos-bc3adblicos-naspec3a7as-de-arthur-miller.pdf>. Acesso em: 01 dez. 2016.

FRYSZMAN, N. D. O teatro iídiche nos Estados Unidos e sua influência na cultura norteamericana. In: BEREZIN, Rifka (Org.). Anais do Simpósio Internacional Cultura Oriental e Cultura Ocidental: Projeções. São Paulo: USP/FFLCH/DLO, 1990. p. 499503.

. "O judeu” de Bernardo Santareno e "As feiticeiras de Salém” de Arthur Miller: uma leitura judaica. Tese de Doutorado - Faculdade de Filosofia, Letras e Ciências Humanas da Universidade de São Paulo. São Paulo, 1989.

KUSHNER, T. Arthur Miller: an appreciation by Tony Kushner. Nova Iorque: The Library of America, 2015.

MASON, J. Stone tower: the political theater of Arthur Miller. Ann Harbor: The University of Michigan Press, 2011.

MILLER, A. After the Fall. A play in two acts. Nova Iorque: Penguin Books, 1964. . All my sons. Nova Iorque: Penguin Books, 1947. . The crucible. Nova Iorque: Penguin Books, 1959. . Death of a salesman. Nova Iorque: Penguin Books, 1961. . Incident at Vichy. Nova Iorque: Viking Penguin, 1985. 
ROZENCHAN, N. A experiência judaica na literatura norte-americana. In: BEREZIN, Rifka (Org.). Anais do Simpósio Internacional Cultura Oriental e Cultura Ocidental: Projeções. São Paulo, USP/FFLCH/DLO, 1990. p. 327-37.

RUSSO, T. P. Análise formal de "All my sons" e de "An enemy of the people", de Arthur Miller. Dissertação de Mestrado - Faculdade de Filosofia, Letras e Ciências Humanas da Universidade de São Paulo. São Paulo, 2014.

SARTRE, J. O Existencialismo é um Humanismo. São Paulo: Nova Cultural, 1987.

WELLAND, D. Miller: The Playwright. Nova Iorque: Methuen, 1983. 